\title{
Treatment decision-making among breast cancer patients in Malaysia
}

\author{
This article was published in the following Dove Press journal: \\ Patient Preference and Adherence \\ 16 October 2017 \\ Number of times this article has been viewed
}

\author{
Yong Hui Nies' \\ Farida Islahudin' \\ Wei Wen Chong' \\ Norlia Abdullah ${ }^{2}$ \\ Fuad Ismail ${ }^{3}$ \\ Ros Suzanna Ahmad \\ Bustamam ${ }^{4}$ \\ Yoke Fui Wong ${ }^{5}$ \\ JJ Saladina ${ }^{2}$ \\ Noraida Mohamed Shah' \\ 'Faculty of Pharmacy, ${ }^{2}$ Department of \\ Surgery, ${ }^{3}$ Department of Radiotherapy \\ and Oncology, Universiti Kebangsaan \\ Malaysia Medical Centre, ${ }^{4}$ Department \\ of Radiotherapy and Oncology, \\ Hospital Kuala Lumpur, Kuala Lumpur, \\ ${ }^{5}$ Department of Radiotherapy and \\ Oncology, National Cancer Institute, \\ Putrajaya, Malaysia
}

Purpose: This study investigated breast cancer patients' involvement level in the treatment decision-making process and the concordance between patients' and physician's perspectives in decision-making.

Participants and methods: A cross-sectional study was conducted involving physicians and newly diagnosed breast cancer patients from three public/teaching hospitals in Malaysia. The Control Preference Scale (CPS) was administered to patients and physicians, and the Krantz Health Opinion Survey (KHOS) was completed by the patients alone. Binary logistic regression was used to determine the association between sociodemographic characteristics, the patients' involvement in treatment decision-making, and patients' preference for behavioral involvement and information related to their disease.

Results: The majority of patients preferred to share decision-making with their physicians (47.5\%), while the second largest group preferred being passive (42.6\%) and a small number preferred being active $(9.8 \%)$. However, the physicians perceived that the majority of patients preferred active decision-making (56.9\%), followed by those who desired shared decisionmaking (32.8\%), and those who preferred passive decision-making (10.3\%). The overall concordance was $26.5 \%$ (54 of 204 patient-physician dyads). The median of preference for information score and behavioral involvement score was 4 (interquartile range [IQR] =3-5) and 2 (IQR $=2-3$ ), respectively. In univariate analysis, the ethnicity and educational qualification of patients were significantly associated with the patients' preferred role in the process of treatment decision-making and the patients' preference for information seeking $(p<0.05)$. However, only educational qualification ( $p=0.004$ ) was significantly associated with patients' preference for information seeking in multivariate analysis.

Conclusion: Physicians failed to understand patients' perspectives and preferences in treatment decision-making. The concordance between physicians' perception and patients' perception was quite low as the physicians perceived that more than half of the patients were active in treatment decision-making. In actuality, more than half of patients perceived that they shared decision-making with their physicians.

Keywords: breast cancer, Control Preference Scale, Krantz Health Opinion Survey, Malaysia, patient-physician dyad, shared decision-making

\section{Introduction}

Breast cancer is the most common cancer in women worldwide and across every single ethnic group in Malaysia. ${ }^{1}$ Unlike in the West, where incidence rates of breast cancer have been stabilized or even diminished, the occurrence of breast cancer has risen in most of the Asian countries in recent years. ${ }^{2}$ The age-standardized incidence rate of breast cancer in Malaysia was 38.7 per 100,000 with 5,410 new cases estimated in 2012 by the International Agency for Research in Cancer (GLOBOCAN). ${ }^{3}$ The rise in the 
incidence of breast cancer may be caused by several factors such as changes in reproductive factors, environmental exposures, dietary intake, and physical activity. ${ }^{2}$

There is a limited research on how patients genuinely make treatment decisions. Patients' preferred role in decision-making has traditionally been neglected during consultations. ${ }^{4}$ Treatment decision-making has evolved from the conventional method, which was solely based on the doctor's decision, to shared decision-making (SDM) that integrates patients' views and perspectives. ${ }^{5,6}$ As such, there is now a demand to identify and monitor complex adverse effects of cancer treatment and to include these in the decision-making process. ${ }^{7}$ van der Weijden et al reported that the clinical practice guidelines can be applied by physicians through the practice of SDM based on generic and specific strategies. ${ }^{8}$ For example, physicians should expand their awareness of available treatment options, taking note of patients' preferences and providing the patient with decision aids during the consultation.

SDM was initially created for life-threatening illnesses where few treatments are available with different possible results. ${ }^{9}$ It is an approach where patients and health care providers work together to make a treatment decision about the latest evidence-based treatment outcome with consideration for the patients' values and preferences. ${ }^{10}$ Furthermore, SDM among physicians and patients has also been shown to diminish patients' internal conflict with respect to treatment options and to increase medication adherence. ${ }^{11}$ It is also believed that SDM would improve patient satisfaction, comprehension, and adherence while promoting patient engagement and self-care to improve their health outcomes. ${ }^{12}$ Limited studies have been conducted on patients' preferred role in decision-making in Malaysia. For example, two studies were conducted which considered the association between SDM and the perception of hypertensive patients ${ }^{13}$ and the association between SDM and patients attending a primary care clinic ${ }^{14}$ for their treatment. Both of these studies showed similar results, with nearly half of the patients preferring SDM, followed by preferring to be passive, and followed by preferring to be active in making treatment decisions.

There were few studies conducted in Australia and United States reporting significant barriers to participation in treatment decision-making among breast cancer patients from minority cultures. ${ }^{15-17}$ Some of the barriers include language difficulties, health literacy, complexity of health care systems, and degree of acculturation. ${ }^{18}$ A study by Claramita et al among patients and physicians in Indonesia, a neighboring country of Malaysia, reported that doctor-patient communication was affected by the cultural characteristics of the patients. ${ }^{19}$ Therefore, this study investigated the perceived and preferred involvement level of breast cancer patients in the treatment decision-making process, sociodemographic factors that influence treatment decision-making, and the concordance between patients' and physicians' perspectives in decision-making.

\section{Materials and methods \\ Sample}

This was a descriptive cross-sectional study carried out at two main public hospitals, Hospital Kuala Lumpur (HKL) and the National Cancer Institute (NCI), and one teaching hospital, Universiti Kebangsaan Malaysia Medical Centre (UKMMC) in Malaysia from July 2016 to January 2017. Ethics approval was obtained from the Research Ethics Committee of Universiti Kebangsaan Malaysia (Ref No: UKM PPI/111/8/JEP-2016-142) and Medical Research \& Ethics Committee, Ministry of Health, Malaysia (Ref No: NMRR16-1085-28980). Patients from HKL, NCI and UKMMC with breast cancer at any stage, diagnosed within the previous 6 months without other malignancy were eligible to be included in this study. Patients with recurrent breast cancer, cognitive impairment, severe illness at the time of study, or language barriers were ineligible for participation. Screened patients were recruited after their consultation with their physician, who initially introduced them to the study. They were given a brief explanation about the study and signed the informed consent form if they agreed to participate. Physicians (breast surgeons/oncologists/medical officers) actively seeing patients were also included in this study upon agreement to participate. Each patient and physician was required to complete a set of questionnaires after the consultation, which was the consultation in which patients made the decision for their treatment.

\section{Measures}

\section{Sociodemographic characteristics}

Patients' information with respect to their gender, age, ethnicity, religion, educational qualification, marital status, employment status, and personal monthly income were recorded.

\section{Instruments}

The Control Preference Scale (CPS) and Krantz Health Opinion Survey (KHOS) were used in this study. Both the questionnaires were translated into Malay and back translated to English by independent bilingual individuals. Content validation was performed by the consultants (oncologists 
and breast surgeon) involved in this study. The translated version was tested in a pilot study with 30 patients who had no trouble in understanding and completing all the questionnaires. No revisions were made to the study measures based on the results of the pilot study.

\section{CPS}

The CPS was created to assess the preferred level of involvement of patients in their treatment decision-making process. $^{20,21}$ In this study, three parallel versions of the CPS (Patient Preference Scale, Patient Perception Scale, and Physician Perception Scale) were used to evaluate the preferred role of patients in the process of decision-making before the consultation, the actual role of patients in the process of decision-making after the consultation, and the perception of physicians on the role of patients in the process of decision-making after the consultation. ${ }^{22}$

The three parallel versions of the CPS consisted of five statements which were then categorized into active decision-making ("I prefer to make the final selection about which treatment I will receive;" "I prefer to make the final selection of my treatment after seriously considering my doctor's opinion;" "I made the final decision about which treatment I would receive;" "I made the final selection of my treatment after seriously considering my doctor's opinion;" "The patient made the final decision about which treatment she would receive;" "The patient made the final decision about which treatment she would receive after seriously considering my opinion"), SDM ("I prefer that my doctor and I share responsibility for deciding which treatment is best for me;" "My doctor and I shared responsibility for deciding which treatment was best for me;" "I shared responsibility with the patient for making the final decision about the treatment she would receive") and passive decision-making ("I prefer that my doctor make the final decision about which treatment will be used, but seriously considers my opinion;" "I prefer to leave all decisions regarding my treatment to my doctor;" "My doctor made the final decision about which treatment would be used, but seriously considered my opinion;" "My doctor made all the decisions regarding my treatment;" "I made the final decision about which treatment the patient would receive after seriously considering the patient's opinion;" "I made the final decision about which treatment the patient would receive"). ${ }^{22}$

The perception level of physicians and patients was also measured in terms of their concordance. This would further explore the ability of physicians to perceive their patients' perception for involvement in treatment decisions. ${ }^{23}$ For ease of analysis, we categorized the active decisionmaking and SDM as an autonomous role, while the role of passive decision-making remained the same, similar to previous studies. ${ }^{14,24}$

\section{KHOS}

The KHOS was developed to measure the preference of patients for different treatment approaches. ${ }^{25}$ This questionnaire has also been widely used in various countries with patients with myocardial infarction ${ }^{26}$ as well as patients undergoing joint arthroplasty ${ }^{27,28}$ and ambulatory surgery. ${ }^{29}$ This instrument consists of two subscales which are the preference for information (KHOS-I) and behavioral involvement (KHOS-B) with seven items and nine items, respectively. This questionnaire has two possible responses, agree $=1$ and disagree $=0$. However, the scoring was reversed for negatively worded items. For the KHOS-B, the range of low scores, medium scores, and high scores are $\leq 2,3-4$, and 5-9, respectively. The range of low scores, medium scores, and high scores for the KHOS-I are $\leq 2,3-5$, and 6-7, respectively. A higher score on the KHOS-I and KHOS-B indicates a higher level of preference for information seeking and higher level of preference for behavioral involvement, respectively. ${ }^{25}$ For ease of analysis, low scores were interpreted as a lower preference level for information seeking and behavioral involvement, and medium and high scores were interpreted as a higher preference level for information seeking and behavioral involvement.

\section{Statistical analysis}

Data were analyzed using SPSS version 21.0 (IBM Corporation, Armonk, NY, USA). Descriptive statistics were used to describe the sample. Binary logistic regression was used to determine the association between the sociodemographic characteristics of patients and patients' preferred role in decision-making, the preference of patients for information seeking, and the preference of patients for behavioral involvement. Univariate analysis was applied to test for an individual predictor with a dependent variable. Consequently, the predictor was included in the multivariate analysis if the criterion ( $p \leq 0.25$ ) was met. ${ }^{30}$ Cohen's kappa coefficient was used to analyze the agreement between the patients and physicians on their perception of treatment decision-making. Pearson's correlation coefficient was also used to determine the two subscales of information and behavioral involvement on the KHOS. A Cohen's kappa value $\leq 0$ indicates no agreement, $0.01-0.20$ none to slight agreement, $0.21-0.40$ fair agreement, 
0.41-0.60 moderate agreement, $0.61-0.80$ substantial agreement, and 0.81-1.00 indicates almost perfect agreement. ${ }^{31}$

\section{Results}

\section{Description of the sample}

A total of 244 patients who fulfilled the inclusion and exclusion criteria were invited to take part in this study. However, only 204 (83.61\%) agreed to participate. The most common reasons for not participating reported by the patients were that they were busy, felt uncomfortable participating, were emotionally unstable, or were being interviewed in another study. Sixty-eight physicians participated in this study. Therefore, there were a total of 204 consultations with physician-patient dyads. Sociodemographic characteristics of the patients are shown in Table 1. The median age of the participants was 55 years (interquartile range $[\mathrm{IQR}]=44.25-62$, range $=23-85$ ). More than half of the participants were Malay (58.3\%), and $52.5 \%$ of participants reported high school as their highest educational qualification. Sociodemographic characteristics of the physicians are shown in Table 2. The median age of the physicians was 31 years (IQR $=29-34$, range $=27-51$ ), and $66.2 \%$ were women. Majority of the physicians were medical officers (86.8\%), and their median duration of general practice was 6 years $(\mathrm{IQR}=4.00-8.75$, range $=1-26)$.

\section{Preferred and perceived roles in decision-making}

The patients' preferred role showed the same pattern with their perceived role in breast cancer treatment decisionmaking. The majority of patients' preference and perception in treatment decision-making was SDM, followed by passive and then active (Table 3). There was a strong agreement between the preferred and perceived roles of patients in treatment decision-making as demonstrated by Cohen's kappa statistics $(k=0.828,95 \%$ CI $[0.750,0.906])$. A total of $51.5 \%$ of patients perceived that they were actually sharing treatment decision-making with their physicians. However, physicians perceived otherwise, stating that they thought most patients were active (56.9\%) in making decisions, followed by SDM (32.8\%), and passivity (10.3\%).

The overall concordance in treatment decision-making between patients and physicians was 26.5\% (54 of 204 patient-physician dyads) with differences in the remaining $73.5 \%$. This can also be seen through the Cohen's Kappa coefficient, which showed almost no agreement between the physicians and patients on the perceived role in treatment decision-making ( $k=0.042,95 \%$ CI $[-0.060,0.144])$.
Table I Sociodemographic characteristics of patients

\begin{tabular}{|c|c|c|c|}
\hline $\begin{array}{l}\text { Characteristics of } \\
\text { patients }\end{array}$ & & $\begin{array}{l}\text { Number of } \\
\text { patients }\end{array}$ & $\begin{array}{l}\text { Percentage } \\
\text { of sample }\end{array}$ \\
\hline \multicolumn{4}{|l|}{ Gender } \\
\hline Male & & I & 0.5 \\
\hline Female & & 203 & 99.5 \\
\hline \multicolumn{4}{|l|}{ Age (years) } \\
\hline $21-40$ & & 31 & 15.2 \\
\hline $4 I-60$ & & 110 & 53.9 \\
\hline $61-80$ & & 60 & 29.4 \\
\hline$>80$ & & 3 & 1.5 \\
\hline Mean \pm SD & $53.98 \pm 12.23$ & & \\
\hline Median (IQR) & 55 (44.25-62) & & \\
\hline Range & $23-85$ & & \\
\hline \multicolumn{4}{|l|}{ Ethnicity } \\
\hline Malay & & 119 & 58.3 \\
\hline Chinese & & 47 & 23.0 \\
\hline Indian & & 33 & 16.2 \\
\hline Other & & 5 & 2.5 \\
\hline \multicolumn{4}{|l|}{ Religion } \\
\hline Muslim & & 122 & 59.8 \\
\hline Buddhist & & 40 & 19.6 \\
\hline Hindu & & 28 & 13.7 \\
\hline Christian & & 9 & 4.4 \\
\hline Catholic & & I & 0.5 \\
\hline Other & & 4 & 2.0 \\
\hline \multicolumn{4}{|l|}{ Educational qualification } \\
\hline No formal education & & 19 & 9.3 \\
\hline Elementary school & & 41 & 20.1 \\
\hline High school & & 107 & 52.5 \\
\hline $\begin{array}{l}\text { Diploma/degree/ } \\
\text { postgraduate }\end{array}$ & & 37 & 18.1 \\
\hline \multicolumn{4}{|l|}{ Marital status } \\
\hline Single & & 29 & 14.2 \\
\hline Married & & 162 & 79.4 \\
\hline Widow & & 6 & 2.9 \\
\hline Divorced & & 7 & 3.4 \\
\hline \multicolumn{4}{|l|}{ Employment status } \\
\hline Employed & & 79 & 38.7 \\
\hline Unemployed & & 125 & 61.3 \\
\hline \multicolumn{4}{|l|}{ Monthly income } \\
\hline$<$ RM250I & & 168 & 82.4 \\
\hline RM250I-RM5000 & & 26 & 12.7 \\
\hline RM5000-RMI0000 & & 10 & 4.9 \\
\hline$>$ RMI0000 & & 0 & 0 \\
\hline
\end{tabular}

Abbreviation: IQR, interquartile range.

\section{Association between patients' sociodemographic characteristics and patients' preferred role in decision-making}

Univariate analysis indicated that ethnicity and educational qualification of patients were significantly associated with patients' preferred role in treatment decision-making. Malay patients were 2.93 times more likely to prefer autonomous role compared to Indian patients (odds ratio $[\mathrm{OR}]=2.93$, $95 \%$ CI $[1.32,6.48], p=0.008)$. Patients with a high school 
Table 2 Sociodemographic characteristics of physicians

\begin{tabular}{ll}
\hline Characteristics & $\mathbf{n}(\%)$ \\
\hline Gender & \\
Male & $23(33.8)$ \\
Female & $45(66.2)$ \\
Ethnicity & \\
Malay & $36(52.9)$ \\
Chinese & $17(25.0)$ \\
Indian & $14(20.6)$ \\
Other & $1(1.5)$ \\
Age (years) & \\
Mean \pm SD & $32.12 \pm 4.42$ \\
Median (IQR) & $31.00(29-34)$ \\
Range & $27-51$ \\
Educational qualification & \\
Medical degree (MD) & $58(85.3)$ \\
MD + MS & $8(11.8)$ \\
MD + MS + subspecialty/fellowship & $2(2.9)$ \\
Country of study & \\
Local & $36(52.9)$ \\
Oversea & $32(47.1)$ \\
General practice (years) & \\
$<5$ years & $22(32.4)$ \\
$5-I 0$ years & $37(54.4)$ \\
$>$ I0 years & $9(13.2)$ \\
Mean \pm SD & $6.94 \pm 4.28$ \\
Median (IQR) & $6.00(4.00-8.75)$ \\
Range & $1-26$ \\
Specialization & \\
Surgeon & $2(2.9)$ \\
Oncologist & $7(10.3)$ \\
Medical officer & $59(86.8)$ \\
\hline
\end{tabular}

Abbreviations: IQR, interquartile range; MS, Physicians with Masters degree.

qualification $(\mathrm{OR}=3.10,95 \% \mathrm{CI}[1.10,8.79], p=0.033)$ and diploma, degree, or postgraduate qualification $(\mathrm{OR}=7.85$, $95 \%$ CI $[2.26,27.26], p=0.001)$ were significantly more likely to prefer an autonomous role in treatment decisionmaking. Nevertheless, only the educational qualification of patients almost significantly associated $(p=0.056)$ with the patients' preferred role, based on the multivariate analysis. Patients with a diploma, degree, or postgraduate qualification were 7.52 times more likely to be autonomous in their decision-making compared to patients with no formal education $(\mathrm{OR}=7.52,95 \%$ CI $[1.66,34.13]$, $p=0.009$; Table 4).

\section{Preferences for information and behavioral involvements}

Patients in this study moderately preferred seeking information, as can be seen from the median KHOS-I score of 4.00 (IQR =3-5). However, the behavioral involvement preference among them was quite low as the median of the KHOS-B score was within the range of low scores at 2.00 $(\mathrm{IQR}=2-3$; Table 5$)$. There was no significant correlation between preference for information and preference for behavioral involvement $(r=0.123, \mathrm{n}=204, p>0.05)$. In a previous study, the Cronbach's alpha for the KHOS was reported as $0.50-0.76$ (KHOS-I) and 0.72-0.77 (KHOS-B). ${ }^{25}$ However, the Cronbach's alpha found in this study was 0.655 and 0.293 for KHOS-I and KHOS-B, respectively. Moreover, the Pearson's correlation showed a weak non-significant linear relationship between the KHOS-I and KHOS-B in this study $(r=0.123, \mathrm{n}=204, p=0.079)$.

The association between patients' sociodemographic characteristics and patients' preference for information seeking is shown in Table 6 . The univariate analysis showed that the ethnicity and educational qualification of the patients were significantly associated with patients' preference for information seeking. Malay patients were 1.92 times more likely to have a higher preference for seeking for information than Indian patients. Patients of other ethnicities were $92 \%$ less likely to seek for information compared to Indian patients $(\mathrm{OR}=0.08,95 \% \mathrm{CI}[0.01,0.82], p=0.034)$. Furthermore, patients with a high school qualification $(\mathrm{OR}=4.46$, $95 \%$ CI $[1.54,12.90], p=0.006)$ and a diploma, degree, or postgraduate qualification $(\mathrm{OR}=6.00,95 \%$ CI $[1.51,23.87]$, $p=0.011$ ) were significantly more likely to have a higher

Table 3 Patients' preferred role (before consultation), patients' perceived role (after consultation), and doctors' perceived patients' role in decision-making (after consultation)

\begin{tabular}{|c|c|c|c|c|c|c|c|}
\hline \multirow{3}{*}{$\begin{array}{l}\text { Patient } \\
\text { perception } \\
\text { scale }\end{array}$} & \multicolumn{3}{|c|}{ Patient preference scale, $\mathbf{n}(\%)$} & \multicolumn{3}{|c|}{ Physician perception scale, $\mathbf{n}(\%)$} & \multirow[t]{3}{*}{ Total, n (\%) } \\
\hline & \multicolumn{2}{|c|}{ Autonomous } & \multirow[t]{2}{*}{ Passive } & \multicolumn{2}{|c|}{ Autonomous } & \multirow[t]{2}{*}{ Passive } & \\
\hline & Active & Shared & & Active & Shared & & \\
\hline \multicolumn{8}{|l|}{ Autonomous } \\
\hline Active & $18(8.8)$ & $0(0)$ & I (0.5) & $10(4.9)$ & $5(2.5)$ & $4(2.0)$ & $19(9.3)$ \\
\hline Shared & $\mathrm{I}(0.5)$ & $93(45.6)$ & II (5.4) & $64(31.4)$ & $34(16.7)$ & $7(3.4)$ & $105(51.5)$ \\
\hline Passive & $\mathrm{I}(0.5)$ & $4(2.0)$ & $75(36.8)$ & $42(20.6)$ & $28(13.7)$ & $10(4.9)$ & $80(39.2)$ \\
\hline Total, n (\%) & $20(9.8)$ & $97(47.5)$ & $87(42.6)$ & $116(56.9)$ & $67(32.8)$ & $21(10.3)$ & $204(100)$ \\
\hline
\end{tabular}

Notes: Concordance: 54 of 204 patient-physician pairs (26.5\%), Cohen's kappa $=0.042, p=0.405$; Agreement between the preferred and the actual participation of patients: Cohen's kappa $=0.828, p<0.00$ I. 
Table 4 Association between patients' sociodemographic characteristics and patients' preferred role in decision-making

\begin{tabular}{|c|c|c|c|c|c|c|c|c|c|c|c|c|}
\hline \multirow{2}{*}{$\begin{array}{l}\text { Characteristics of } \\
\text { patients }\end{array}$} & \multirow{2}{*}{$\begin{array}{l}\text { Autonomous } \\
n=117 \\
n(\%)\end{array}$} & \multirow{2}{*}{$\begin{array}{l}\begin{array}{l}\text { Passive } \\
\mathrm{n}=87\end{array} \\
\mathrm{n}(\%)\end{array}$} & \multicolumn{5}{|c|}{ Univariate analysis } & \multicolumn{5}{|c|}{ Multivariate analysis } \\
\hline & & & \multicolumn{2}{|c|}{$\begin{array}{l}\text { Crude OR } \\
(95 \% \mathrm{Cl})\end{array}$} & \multicolumn{2}{|c|}{$\begin{array}{l}\chi^{2} \text {-statistics } \\
(\mathrm{df})\end{array}$} & \multirow{2}{*}{$\begin{array}{l}\boldsymbol{P} \text {-value } \\
0.843\end{array}$} & \multicolumn{2}{|c|}{$\begin{array}{l}\text { Adjusted OR } \\
(95 \% \mathrm{Cl})\end{array}$} & \multicolumn{2}{|c|}{$\begin{array}{l}\chi^{2} \text {-statistics } \\
(d f)\end{array}$} & \multirow[t]{2}{*}{$p$-value } \\
\hline Age (years) & & & & & 0.83 & (3) & & & & & & \\
\hline $21-40$ & $19(9.3)$ & $12(5.9)$ & Ref & - & & & & & & & & \\
\hline $4 I-60$ & $60(29.4)$ & $50(24.5)$ & 0.76 & $(0.34, I .7 I)$ & 0.45 & (I) & 0.505 & & & & & \\
\hline $61-80$ & $36(17.6)$ & $24(11.8)$ & 0.95 & $(0.39,2.30)$ & 0.01 & (I) & 0.905 & & & & & \\
\hline$>80$ & $2(1.0)$ & $\mathrm{I}(0.5)$ & 1.26 & $(0.10,15.50)$ & 0.03 & (I) & 0.855 & & & & & \\
\hline Ethnicity & & & & & 9.99 & (3) & $0.019^{a}$ & & & 3.37 & (3) & 0.338 \\
\hline Malay & 78 (38.2) & $4 I(20.1)$ & 2.93 & $(1.32,6.48)$ & 7.03 & (I) & 0.008 & 2.53 & $(0.11,59.94)$ & 0.33 & (I) & 0.565 \\
\hline Chinese & $25(12.3)$ & $22(10.8)$ & 1.75 & $(0.7 \mathrm{I}, 4.3 \mathrm{I})$ & 1.47 & (I) & 0.225 & 5.06 & $(0.40,63.88)$ & 1.57 & (I) & 0.210 \\
\hline Indian & $13(6.4)$ & $20(9.8)$ & Ref & - & & & & Ref & - & & & \\
\hline Others & $\mathrm{I}(0.5)$ & $4(2.0)$ & 0.39 & $(0.04,3.84)$ & 0.66 & (I) & 0.415 & 0.57 & $(0.03,12.82)$ & 0.13 & (I) & 0.723 \\
\hline Religion & & & & & 7.85 & (3) & 0.049 & & & 1.63 & (3) & 0.652 \\
\hline Muslim & 79 (38.7) & $43(2 I . I)$ & 2.84 & $(I .22,6.6 I)$ & 5.87 & (I) & 0.015 & 1.04 & $(0.04,26.46)$ & 0 & (I) & 0.983 \\
\hline Buddhist & $19(9.3)$ & $2 I(10.3)$ & 1.40 & $(0.53,3.73)$ & 0.45 & (I) & 0.503 & 0.38 & $(0.03,5.76)$ & 0.49 & (I) & 0.485 \\
\hline Hindu & II (5.4) & $17(8.3)$ & Ref & - & & & & Ref & & & & \\
\hline Others & $8(3.9)$ & $6(2.9)$ & 2.06 & $(0.56,7.58)$ & 1.18 & (I) & 0.276 & 1.20 & $(0.15,9.88)$ & 0.03 & (I) & 0.866 \\
\hline Educational qualification & & & & & 12.94 & (3) & $0.005^{\mathrm{a}}$ & & & 7.55 & (3) & 0.056 \\
\hline No formal education & $6(2.9)$ & $13(6.4)$ & Ref & - & & & & Ref & - & & & \\
\hline Elementary school & $19(9.3)$ & $22(10.8)$ & 1.87 & $(0.60,5.88)$ & 1.15 & (I) & 0.284 & 1.93 & $(0.58,6.44)$ & 1.13 & (I) & 0.287 \\
\hline High school & $63(30.9)$ & $44(21.6)$ & 3.10 & $(1.10,8.79)$ & 4.54 & (I) & 0.033 & 2.99 & $(0.96,9.30)$ & 3.59 & (I) & 0.058 \\
\hline $\begin{array}{l}\text { Diploma/degree/ } \\
\text { postgraduate }\end{array}$ & $29(14.2)$ & $8(3.9)$ & 7.85 & $(2.26,27.26)$ & 10.54 & (I) & 0.001 & 7.52 & $(1.66,34.13)$ & 6.84 & (I) & 0.009 \\
\hline Marital status & & & & & 0.25 & (3) & 0.969 & & & & & \\
\hline Single & $17(8.3)$ & $12(5.9)$ & Ref & - & & & & & & & & \\
\hline Married & $92(45.1)$ & $70(34.3)$ & 0.93 & $(0.42,2.07)$ & 0.03 & (I) & 0.854 & & & & & \\
\hline Widow & $4(2.0)$ & $2(1.0)$ & 1.41 & $(0.22,8.99)$ & 0.13 & (I) & 0.715 & & & & & \\
\hline Divorced & $4(2.0)$ & $3(1.5)$ & 0.94 & $(0.18,5.00)$ & 0.01 & (I) & 0.943 & & & & & \\
\hline \multicolumn{13}{|l|}{ Employment status } \\
\hline Employed & $49(24.0)$ & $30(14.7)$ & 1.37 & $(0.77,2.43)$ & 1.15 & (I) & 0.284 & & & & & \\
\hline Unemployed & $68(33.3)$ & $57(27.9)$ & Ref & - & & & & & & & & \\
\hline Monthly income & & & & & 3.03 & $(2)$ & 0.220 & & & 0.29 & (2) & 0.866 \\
\hline$<$ RM250I & $92(45.1)$ & $76(37.3)$ & Ref & - & & & & Ref & - & & & \\
\hline RM250I-RM5000 & $17(8.3)$ & $9(4.4)$ & 1.56 & $(0.66,3.70)$ & 1.02 & (I) & 0.312 & 0.77 & $(0.28,2.09)$ & 0.27 & (I) & 0.604 \\
\hline RM5000-RMI0000 & $8(3.9)$ & $2(1.0)$ & 3.30 & $(0.68,16.03)$ & 2.20 & (I) & 0.135 & 0.99 & $(0.15,6.56)$ & 0 & (I) & 0.988 \\
\hline
\end{tabular}

Notes: Autonomous: shared and active role preference; passive: passive role preference; ${ }^{a}$ indicates the predictor(s) with significant difference.

Abbreviations: $\mathrm{OR}$, odds ratio; $\mathrm{Cl}$, confidence interval.

preference level for seeking information compared to those with no formal education. Based on multivariate analysis, educational qualification and marital status of patients were significant predictors of patients' preference for information seeking. Patients with a high school qualification $(\mathrm{OR}=5.38$, $95 \%$ CI $[1.59,18.14], p=0.007)$ and a diploma, degree, or postgraduate qualification $(\mathrm{OR}=6.67,95 \% \mathrm{CI}[1.37,32.37]$, $p=0.019$ ) were more likely to have higher preference for seeking information compared to those with no formal education. Overall, marital status was found to be significantly associated with preference for seeking information. However, being married, widowed, or divorced was not significantly associated with preference for seeking information when compared with being single (Table 6).
None of the sociodemographic characteristics were found to be significantly associated with behavioral involvement preferences, as was found in the univariate analysis (Table 7).

\section{Discussion}

This study showed that most of the patients with breast cancer preferred SDM and passivity rather than being active in the process of decision-making. This finding was similar to a study carried out at a primary care clinic of a teaching hospital in Kuala Lumpur, which showed that most of the patients attending the clinic $(51.9 \%)$ preferred SDM, followed by being passive (26.3\%) and being active $(21.8 \%)$ in decision-making. ${ }^{14}$ Many studies have reported that most 
Table 5 Preferences for information and behavioral involvements of patients

\begin{tabular}{|c|c|c|c|c|}
\hline Krantz Health Opinion Survey (KHOS) item & $\begin{array}{l}\text { Agree } \\
\text { n (\%) }\end{array}$ & $\begin{array}{l}\text { Disagree } \\
\text { n (\%) }\end{array}$ & $\begin{array}{l}\text { Score } \\
\text { Mean } \pm \text { SD } \\
\text { Median (IQR) } \\
\text { Range }\end{array}$ & $\begin{array}{l}\text { Cronbach's } \\
\text { alpha }\end{array}$ \\
\hline Information subscale (KHOS-I) & & & $\begin{array}{l}3.66 \pm 1.47 \\
4.00(3-5) \\
0-7\end{array}$ & 0.655 \\
\hline $\begin{array}{l}\text { I usually don't ask the doctor or the nurse many questions about } \\
\text { what they're doing during a medical exam. (I })^{\mathrm{a}}\end{array}$ & $165(80.9)$ & $39(19.1)$ & & \\
\hline $\begin{array}{l}\text { l'd rather have doctors and nurses make the decisions about what's } \\
\text { best than for them to give me a whole lot of choices. (3) }\end{array}$ & $5(2.5)$ & $199(97.5)$ & & \\
\hline $\begin{array}{l}\text { Instead of waiting for them to tell me, I usually ask the doctor or } \\
\text { nurse immediately after an examination about my health. (4) }\end{array}$ & $130(63.7)$ & $74(36.3)$ & & \\
\hline $\begin{array}{l}\text { I usually ask the doctor or nurse lots of experience about the } \\
\text { procedures during a medical exam. (8) }\end{array}$ & $180(88.2)$ & $24(11.8)$ & & \\
\hline $\begin{array}{l}\text { It is better to trust the doctor or nurse in charge of medical } \\
\text { procedure than to question what they are doing. }(10)^{\mathrm{a}}\end{array}$ & $4(2.0)$ & $200(98.0)$ & & \\
\hline $\begin{array}{l}\text { I usually wait for the doctor or the nurse to tell me the results of a } \\
\text { medical examination rather than asking them immediately. }(15)^{\mathrm{a}}\end{array}$ & $97(47.5)$ & $107(52.5)$ & & \\
\hline $\begin{array}{l}\text { I'd rather be given many choices about what's best for my health then } \\
\text { to have the doctor make the decision for me. (16) }\end{array}$ & $165(80.9)$ & $39(19.1)$ & & \\
\hline Behavioral involvement subscale (KHOS-B) & & & $\begin{array}{l}2.20 \pm 0.84 \\
2.00(2-3) \\
0-5\end{array}$ & 0.293 \\
\hline $\begin{array}{l}\text { Except for serious illness, it is generally better to take care of your } \\
\text { own health than to seek professional help. ( } 2 \text { ) }\end{array}$ & $193(94.6)$ & II (5.4) & & \\
\hline $\begin{array}{l}\text { It is better to reply on the judgements of doctors (who are experts) } \\
\text { than to rely on "common sense" in taking care of your own body. (5) }\end{array}$ & $2(1.0)$ & $202(99.0)$ & & \\
\hline $\begin{array}{l}\text { Clinics and hospitals are good places to go for help since it is best for } \\
\text { medical experts to take responsibility for health care. }(6)^{a}\end{array}$ & $0(0)$ & $204(100)$ & & \\
\hline $\begin{array}{l}\text { Learning how to cure some of your illness without contacting a } \\
\text { physician is a good idea. ( } 7)\end{array}$ & $100(49.0)$ & $104(5 \mathrm{I} .0)$ & & \\
\hline $\begin{array}{l}\text { It's almost always better to seek professional help than to try to treat } \\
\text { yourself. }(9)^{\mathrm{a}}\end{array}$ & I (0.5) & $203(99.5)$ & & \\
\hline $\begin{array}{l}\text { Learning how to cure some of your illness without contacting a } \\
\text { physician may create more harm than good. }(\mathrm{II})^{\mathrm{a}}\end{array}$ & $3(1.5)$ & $20 \mathrm{I}(98.5)$ & & \\
\hline $\begin{array}{l}\text { Recovery is usually quicker under care of a doctor or a nurse than } \\
\text { when patients take care of themselves. }(12)^{\mathrm{a}}\end{array}$ & $0(0)$ & $204(100)$ & & \\
\hline $\begin{array}{l}\text { If it costs the same, l'd rather have a doctor or a nurse give me } \\
\text { treatments than to do the same treatments myself. }(13)^{\mathrm{a}}\end{array}$ & $0(0)$ & $204(100)$ & & \\
\hline $\begin{array}{l}\text { It is better to rely less on physicians and more on your own common } \\
\text { sense when it comes to caring for your body. (14) }\end{array}$ & $149(73.0)$ & $55(27.0)$ & & \\
\hline Total KHOS & & & $\begin{array}{l}5.85 \pm I .78 \\
6.00(5-7) \\
I-12\end{array}$ & 0.578 \\
\hline
\end{tabular}

Notes: Pearson correlation coefficient between the two subscales, $r=0.123, n=204, p=0.079$; andicates negatively worded item.

Abbreviations: SD, standard deviation; IQR, interquartile range.

patients preferred SDM as being the most satisfactory. ${ }^{32-34}$ Before seeing the doctor, the majority of the patients in this study perceived that their role in actual decision-making was similar to their preferences in treatment decision-making. However, physicians perceived that their patients actually made the treatment decision themselves rather than through SDM. These findings were similar to a previous study with elderly patients with higher-risk myelodysplastic syndromes, which found the perceptions of physicians of patients' preferences for involvement in treatment decision-making was always different from their patients' preferred role. ${ }^{23}$ In the present study, physicians perceived that their patients desired the same treatment decision-making only in a quarter of the cases. This highlights a failure of the physicians to accurately identify their patients' preference in treatment decision-making for breast cancer. Therefore, it is necessary 
Table 6 Association between patients' sociodemographic characteristics and patients' preference of information seeking

\begin{tabular}{|c|c|c|c|c|c|c|c|c|c|c|c|c|}
\hline \multirow{2}{*}{$\begin{array}{l}\text { Characteristics of } \\
\text { patients }\end{array}$} & \multirow{2}{*}{$\begin{array}{l}\text { Higher } \\
\text { preference } \\
\text { level } \\
\mathrm{n}=162 \\
\mathrm{n}(\%)\end{array}$} & \multirow{2}{*}{$\begin{array}{l}\text { Lower } \\
\text { preference } \\
\text { level } \\
\mathrm{n}=42 \\
\mathrm{n}(\%)\end{array}$} & \multicolumn{5}{|c|}{ Univariate analysis } & \multicolumn{5}{|c|}{ Multivariate analysis } \\
\hline & & & \multicolumn{2}{|c|}{$\begin{array}{l}\text { Crude OR } \\
(95 \% \mathrm{Cl})\end{array}$} & \multicolumn{2}{|c|}{$\begin{array}{l}\chi^{2} \text {-statistics } \\
(d f)\end{array}$} & \multirow{2}{*}{$\begin{array}{l}\text { p-value } \\
0.552\end{array}$} & \multicolumn{2}{|c|}{$\begin{array}{l}\text { Adjusted OR } \\
(95 \% \mathrm{CI})\end{array}$} & \multicolumn{2}{|c|}{$\begin{array}{l}\chi^{2} \text {-statistics } \\
(\mathrm{df})\end{array}$} & \multirow[t]{2}{*}{$p$-value } \\
\hline Age (years) & & & & & 2.10 & (3) & & & & & & \\
\hline $21-40$ & $27(13.2)$ & $4(2.0)$ & Ref & - & & & & & & & & \\
\hline $4 I-60$ & $88(43.1)$ & $22(10.8)$ & 0.59 & $(0.19,1.87)$ & 0.80 & (I) & 0.372 & & & & & \\
\hline $61-80$ & $45(22.1)$ & $15(7.4)$ & 0.44 & $(0.13,1.48)$ & 1.75 & (I) & 0.186 & & & & & \\
\hline$>80$ & $2(1.0)$ & $\mathrm{I}(0.5)$ & 0.30 & $(0.02,4.07)$ & 0.83 & (I) & 0.363 & & & & & \\
\hline Ethnicity & & & & & $|0.5|$ & (3) & $0.015^{\mathrm{a}}$ & & & 4.76 & (3) & 0.190 \\
\hline Malay & $102(50.0)$ & $17(8.3)$ & 1.92 & $(0.75,4.95)$ & 1.82 & (I) & 0.177 & 4.78 & $(0.15,158.3)$ & 0.77 & (I) & 0.381 \\
\hline Chinese & $34(16.7)$ & $13(6.4)$ & 0.84 & $(0.30,2.32)$ & 0.12 & (I) & 0.733 & 0.75 & $(0.04,13.58)$ & 0.04 & (I) & 0.847 \\
\hline Indian & $25(12.3)$ & $8(3.9)$ & Ref & - & & & & Ref & - & & & \\
\hline Others & $\mathrm{I}(0.5)$ & $4(2.0)$ & 0.08 & $(0.01,0.82)$ & 4.51 & (I) & 0.034 & 0.14 & $(0.01,3.50)$ & 1.44 & (I) & 0.230 \\
\hline Religion & & & & & 5.16 & (3) & 0.161 & & & 0.78 & (3) & 0.853 \\
\hline Muslim & $103(50.5)$ & $19(9.3)$ & 1.81 & $(0.67,4.84)$ & 1.39 & (I) & 0.239 & 0.33 & $(0.01,11.98)$ & 0.36 & (I) & 0.547 \\
\hline Buddhist & $29(14.2)$ & II (5.4) & 0.88 & $(0.29,2.64)$ & 0.05 & (I) & 0.818 & 1.89 & $(0.08,42.44)$ & 0.16 & (I) & 0.688 \\
\hline Hindu & $21(10.3)$ & $7(3.4)$ & Ref & - & & & & Ref & & & & \\
\hline Others & $9(4.4)$ & $5(2.5)$ & 0.60 & $(0.15,2.40)$ & 0.52 & (I) & $0.47 I$ & 1.43 & $(0.10,20.92)$ & 0.07 & (I) & 0.794 \\
\hline Educational qualification & & & & & $15.4 \mathrm{I}$ & (3) & $0.002^{\mathrm{a}}$ & & & 13.78 & (3) & $0.003^{\mathrm{a}}$ \\
\hline No formal education & II (5.4) & $8(3.9)$ & Ref & - & & & & Ref & - & & & \\
\hline Elementary school & $26(12.7)$ & $15(7.4)$ & 1.26 & $(0.42,3.83)$ & 0.17 & $(\mathrm{I})$ & 0.683 & 1.22 & $(0.37,4.02)$ & 0.11 & (I) & 0.743 \\
\hline High school & $92(45.1)$ & $15(7.4)$ & 4.46 & $(1.54,12.90)$ & 7.62 & (I) & 0.006 & 5.38 & $(1.59,18.14)$ & 7.35 & (I) & $0.007^{a}$ \\
\hline $\begin{array}{l}\text { Diploma/degree/ } \\
\text { postgraduate }\end{array}$ & $33(16.2)$ & $4(2.0)$ & 6.00 & $(1.51,23.87)$ & 6.47 & (I) & 0.011 & 6.67 & $(1.37,32.37)$ & 5.54 & (I) & $0.019^{a}$ \\
\hline Marital status & & & & & 6.57 & (3) & 0.087 & & & 8.97 & (3) & $0.030^{\mathrm{a}}$ \\
\hline Single & $21(10.3)$ & $8(3.9)$ & Ref & - & & & & Ref & - & & & \\
\hline Married & $134(65.7)$ & $28(13.7)$ & 1.82 & $(0.73,4.53)$ & 1.67 & (I) & 0.196 & 2.18 & $(0.8 \mathrm{I}, 5.87)$ & 2.37 & (I) & 0.123 \\
\hline Widow & $3(1.5)$ & $3(1.5)$ & 0.38 & $(0.06,2.29)$ & 1.11 & (I) & 0.292 & 0.27 & $(0.04,1.92)$ & 1.71 & (I) & 0.191 \\
\hline Divorced & $4(2.0)$ & $3(1.5)$ & 0.51 & $(0.09,2.79)$ & 0.61 & (I) & 0.436 & 0.37 & $(0.05,2.59)$ & 1.00 & (I) & 0.317 \\
\hline \multicolumn{13}{|l|}{ Employment status } \\
\hline Employed & $61(29.9)$ & I8 (8.8) & 0.81 & $(0.40,1.60)$ & 0.38 & (I) & 0.538 & & & & & \\
\hline Unemployed & $101(49.5)$ & $24(11.8)$ & Ref & & & & & & & & & \\
\hline Monthly income & & & & & 0 & $(2)$ & 1.000 & & & & & \\
\hline$<$ RM250I & $126(61.8)$ & $42(20.6)$ & Ref & - & & & & & & & & \\
\hline RM250I-RM5000 & $26(12.7)$ & $0(0)$ & $>999$ & $(0)$ & 0 & (I) & 0.998 & & & & & \\
\hline RM5000-RMI0000 & $10(4.9)$ & $0(0)$ & $>999$ & $(0)$ & 0 & (I) & 0.999 & & & & & \\
\hline
\end{tabular}

Notes: Higher preference level: medium scores (3-5) and high scores (6-7) of KHOS-l; lower preference level: low scores ( $\leq 2)$ of KHOS-I. andicates the predictor(s) with significant difference.

Abbreviations: $\mathrm{OR}$, odds ratio; $\mathrm{Cl}$, confidence interval.

for physicians to inquire about patients' preferred role in order to meet patients' expectation in deciding on treatment for their disease. ${ }^{22}$

In this study, the univariate analysis indicates that the ethnicity and educational qualification of patients were significantly associated with the patients' preferred role in treatment decision-making. Malay patients were significantly more likely to prefer an autonomous role compared to Indian patients by nearly three times. This may be due to Malay patients being more able to communicate fluently in their native language with the physicians, unlike the Indian patients. However, multivariate analysis indicated that only educational qualification was almost marginally associated ( $p=0.056$ ) with the patients' preferred role in treatment decision-making. Patients who were more educated may likewise have an increased perception to the move toward an autonomous role as they would actively seek information for different treatment options. . $^{21,35,36}$

The scores for preference for information seeking were higher than the scores for behavioral involvement in this study. Previous studies reported that patients preferred to be completely informed about their illness regardless of their preferred role in decision-making..$^{24,37,38}$ In this study, the weak relationship between the KHOS-I and 
Table 7 Association between patients' sociodemographic characteristics and patients' preference of behavior involvement

\begin{tabular}{|c|c|c|c|c|c|c|c|}
\hline \multirow{2}{*}{$\begin{array}{l}\text { Characteristics of } \\
\text { patients }\end{array}$} & \multirow{2}{*}{$\begin{array}{l}\text { Higher } \\
\text { preference } \\
\text { level } \\
\mathrm{n}=\mathbf{7 9} \\
\mathrm{n}(\%)\end{array}$} & \multirow{2}{*}{$\begin{array}{l}\text { Lower } \\
\text { preference } \\
\text { level } \\
\mathrm{n}=\mathbf{I} 25 \\
\mathrm{n}(\%)\end{array}$} & \multicolumn{5}{|c|}{ Univariate analysis } \\
\hline & & & \multicolumn{2}{|c|}{ Crude OR (95\% Cl) } & \multicolumn{2}{|c|}{$\begin{array}{l}\chi^{2} \text {-statistics } \\
(\mathrm{df})\end{array}$} & \multirow{2}{*}{$\begin{array}{l}p \text {-value } \\
0.802\end{array}$} \\
\hline Age (years) & & & & & 1.00 & (3) & \\
\hline $21-40$ & $12(5.9)$ & $19(9.3)$ & Ref & - & & & \\
\hline $4 I-60$ & $43(21.1)$ & $67(32.8)$ & 1.02 & $(0.45,2.30)$ & 0 & (I) & 0.969 \\
\hline $6 I-80$ & $22(10.8)$ & $38(18.6)$ & 0.92 & $(0.38,2.24)$ & 0.04 & (I) & 0.849 \\
\hline$>80$ & $2(1.0)$ & $I(0.5)$ & 3.17 & $(0.26,38.85)$ & 0.81 & (I) & 0.367 \\
\hline Ethnicity & & & & & 1.91 & (3) & 0.591 \\
\hline Malay & $43(2 \mathrm{I} . \mathrm{I})$ & $76(37.3)$ & 0.77 & $(0.35,1.68)$ & 0.44 & (I) & 0.510 \\
\hline Chinese & $21(10.3)$ & $26(12.7)$ & 1.10 & $(0.45,2.69)$ & 0.04 & (I) & $0.84 I$ \\
\hline Indian & $14(6.9)$ & $19(9.3)$ & Ref & - & & & \\
\hline Others & $\mathrm{I}(0.5)$ & $4(2.0)$ & 0.34 & $(0.03,3.38)$ & 0.85 & (I) & 0.356 \\
\hline Religion & & & & & 3.32 & (3) & 0.345 \\
\hline Muslim & $45(22.1)$ & 77 (37.7) & 0.78 & $(0.34,1.79)$ & 0.34 & (I) & 0.558 \\
\hline Buddhist & $19(9.3)$ & $21(10.3)$ & 1.21 & $(0.46,3.19)$ & 0.14 & (I) & 0.705 \\
\hline Hindu & $12(5.9)$ & $16(7.8)$ & Ref & - & & & \\
\hline Others & $3(1.5)$ & II (5.4) & 0.36 & $(0.08,1.60)$ & 1.80 & (I) & 0.180 \\
\hline Educational qualification & & & & & 1.18 & (3) & 0.758 \\
\hline No formal education & $6(2.9)$ & $13(6.4)$ & Ref & - & & & \\
\hline Elementary school & $14(6.9)$ & $27(13.2)$ & 1.12 & $(0.35,3.59)$ & 0.04 & (I) & 0.844 \\
\hline High school & $43(21.1)$ & $64(31.4)$ & 1.46 & $(0.5 \mathrm{I}, 4.13)$ & 0.50 & (I) & 0.480 \\
\hline $\begin{array}{l}\text { Diploma/degree/ } \\
\text { postgraduate }\end{array}$ & $16(7.8)$ & $21(10.3)$ & 1.65 & $(0.52,5.30)$ & 0.71 & (I) & 0.399 \\
\hline Marital status & & & & & 2.07 & (3) & 0.559 \\
\hline Single & II (5.4) & I8 (8.8) & Ref & - & & & \\
\hline Married & $63(30.9)$ & $99(48.5)$ & $\mathrm{I}, 040.33$ & $(0.46,2.35)$ & 0.01 & (I) & 0.922 \\
\hline Widow & $\mathrm{I}(0.5)$ & $5(2.5)$ & 2.18 & $(0.03,3.18)$ & 0.93 & (I) & 0.336 \\
\hline Divorced & $4(2.0)$ & $3(1.5)$ & & $(0.4 I, 11.64)$ & 0.83 & (I) & 0.361 \\
\hline \multicolumn{8}{|l|}{ Employment status } \\
\hline Employed & $37(18.1)$ & $42(20.6)$ & 1.74 & $(0.98,3.10)$ & 3.55 & (I) & 0.060 \\
\hline Unemployed & $42(20.6)$ & $83(40.7)$ & Ref & - & & & \\
\hline Monthly income & & & & & 0.71 & $(2)$ & 0.701 \\
\hline$<$ RM250I & 65 (31.9) & $103(50.5)$ & Ref & - & & & \\
\hline RM250I-RM5000 & $9(4.4)$ & $17(8.3)$ & 0.84 & $(0.35,1.99)$ & 0.16 & (I) & 0.691 \\
\hline RM5000-RMI0000 & $5(2.5)$ & $5(2.5)$ & 1.59 & $(0.44,5.69)$ & 0.50 & (I) & 0.480 \\
\hline
\end{tabular}

Notes: Higher preference level: medium scores (3-4) and high scores (5-9) of KHOS-B; lower preference level: low scores ( $\leq 2)$ of KHOS-B. Abbreviations: $\mathrm{OR}$, odds ratio; $\mathrm{Cl}$, confidence interval.

KHOS-B indicated that patients preferred to gain information regarding their disease and treatment options rather than being involved in treatment decision-making. Ethnicity, educational qualification, and marital status were found to be associated with the preference for information seeking. This may be explained by the fact that educated patients are better able to communicate with their physicians. Communication is essential between patients and physicians during consultations as it allows the physicians to understand patients' perceptions and expectations regarding the treatment of the disease. However, physicians must provide information about the disease and treatment options as well as the expected outcomes for their patients as this may help patients to understand their condition. ${ }^{25}$ It is also essential for physicians to know their patients' desired behavioral involvement in deciding their treatment during the consultation. As seen in this study, patients' preference for information seeking and behavioral involvement were more likely to rely on individual patients' preferences. ${ }^{39}$

A limitation of this study was on the low internal consistencies for KHOS-I and KHOS-B (Cronbach's alpha: 0.655 and 0.293 , respectively) compared to the values reported in the original paper [0.50-0.76 (KHOS-I) and 0.72-0.77 (KHOS-B)]. ${ }^{25}$ This needs to be probed further in future 
as the patients may have poor understanding on the questions asked.

\section{Conclusion}

Most of the patients in this study preferred SDM and being passive rather than active in breast cancer treatment decision-making. Physicians, however, perceived that patients preferred to be active. The overall concordance between the physicians and patients was quite low, indicating the importance of communication for better understanding of patients' preference in treatment decision-making.

\section{Acknowledgments}

We would like to thank Mrs Tassha Hilda, statistician of Clinical Research Centre for statistical consultation, and all the physicians and staff nurses of UKM Medical Centre, Hospital Kuala Lumpur and National Cancer Institute. We would also like to thank Universiti Kebangsaan Malaysia for funding this research (grant code: KOMUNITI-2014-009). We acknowledge the Director General of the Ministry of Health, Malaysia for permission to publish this article.

\section{Disclosure}

The authors report no conflicts of interest in this work.

\section{References}

1. Beshir SA, Hanipah MA. Knowledge, perception, practice and barriers of breast cancer health promotion activities among community pharmacists in two Districts of Selangor state, Malaysia. Asian Pac J Cancer Prev. 2012;13(9):4427-4430.

2. Pathy NB, Yip CH, Taib NA, et al. Breast cancer in a multi-ethnic Asian setting: results from the Singapore-Malaysia hospital-based breast cancer registry. Breast. 2011;20:S75-S80.

3. Weng B, Wang Q, San Lin YL. Nasal cavity metastasis of breast cancer: a case report and review of the literature. Int J Clin Exp Pathol. 2014;7(10):7028.

4. Wirtz V, Cribb A, Barber N. Patient-doctor decision-making about treatment within the consultation - a critical analysis of models. Soc Sci Med. 2006;62(1):116-124.

5. Sandman L, Munthe C. Shared decision-making and patient autonomy. Theor Med Bioeth. 2009;30(4):289-310.

6. Cribb A, Entwistle VA. Shared decision making: trade-offs between narrower and broader conceptions. Health Expect. 2011;14(2):210-219.

7. Kanatas A, Velikova G, Roe B, et al. Patient-reported outcomes in breast oncology: a review of validated outcome instruments. Tumori. 2012; 98(6):678-688.

8. van der Weijden T, Pieterse AH, Koelewijn-van Loon MS, et al. How can clinical practice guidelines be adapted to facilitate shared decision making? A qualitative key-informant study. BMJ Qual Saf. 2013; 22(10):855-863.

9. Charles C, Gafni A, Whelan T. Shared decision-making in the medical encounter: what does it mean? (or it takes at least two to tango). Soc Sci Med. 1997;44(5):681-692.

10. Joosten EA, DeFuentes-Merillas L, De Weert GH, Sensky T, Van Der Staak CPF, de Jong CA. Systematic review of the effects of shared decision-making on patient satisfaction, treatment adherence and health status. Psychother Psychosom. 2008;77(4):219-226.
11. Wilson SR, Strub P, Buist AS, et al. Shared treatment decision making improves adherence and outcomes in poorly controlled asthma. Am J Respir Crit Care Med. 2010;181(6):566-577.

12. Garrard F, Ridd M, Narayan H, Montgomery AA. Decisions, choice and shared decision making in antenatal clinics: an observational study. Patient Educ Counsel. 2015;98(9):1106-1111.

13. Mah HC, Muthupalaniappen L, Chong WW. Perceived involvement and preferences in shared decision-making among patients with hypertension. Family Pract. 2016;33(3):296-301.

14. Ambigapathy R, Chia YC, Ng CJ. Patient involvement in decisionmaking: a cross-sectional study in a Malaysian primary care clinic. BMJ Open. 2016;6(1):e010063.

15. Shaw J, Zou X, Butow P. Treatment decision making experiences of migrant cancer patients and their families in Australia. Patient Educ Counsel. 2015;98(6):742-747.

16. López ME, Kaplan CP, Nápoles AM, Hwang ES, Livaudais JC, Karliner LS. Satisfaction with treatment decision-making and treatment regret among Latinas and non-Latina whites with DCIS. Patient Educ Counsel. 2014;94(1):83-89.

17. Nedjat-Haiem FR, Lorenz KA, Ell K, Hamilton A, Palinkas L. Experiences with advanced cancer among Latinas in a public health care system. J Pain Sympt Manag. 2012;43(6):1013-1024.

18. Kwok C, Koo FK. Participation in treatment decision-making among Chinese-Australian women with breast cancer. Support Care Cancer. 2017;25(3):957-963.

19. Claramita M, Nugraheni MD, van Dalen J, van der Vleuten C. Doctor-patient communication in Southeast Asia: a different culture? Adv Health Sci Educ. 2013:1-17.

20. Degner LF, Sloan JA. Decision making during serious illness: what role do patients really want to play? J Clin Epidemiol. 1992;45(9): 941-950.

21. Degner LF, Sloan JA, Venkatesh P. The control preferences scale. Can J Nurs Res Arch. 1997;29(3):21-43.

22. Janz NK, Wren PA, Copeland LA, Lowery JC, Goldfarb SL, Wilkins EG. Patient-physician concordance: preferences, perceptions, and factors influencing the breast cancer surgical decision. JClin Oncol. 2004;22(15):3091-3098.

23. Caocci G, Voso MT, Angelucci E, et al. Accuracy of physician assessment of treatment preferences and health status in elderly patients with higher-risk myelodysplastic syndromes. Leuk Res. 2015;39(8): 859-865.

24. Solari A, Martinelli V, Trojano M, et al. An information aid for newly diagnosed multiple sclerosis patients improves disease knowledge and satisfaction with care. Mult Scler J. 2010;16(11):1393-1405.

25. Krantz DS, Baum A, Wideman MV. Assessment of preferences for self-treatment and information in health care. J Pers Soc Psychol. 1980; 39(5):977-990.

26. Nilsson UG, Ivarsson B, Alm-Roijer C, Svedberg P. The desire for involvement in health care, anxiety and coping in patients and their partners after a myocardial infarction. Eur J Cardiovasc Nurs. 2013; $12(5): 461-467$.

27. Ingadottir B, Johansson Stark Å, Leino-Kilpi H, Sigurdardottir AK, Valkeapää K, Unosson M. The fulfilment of knowledge expectations during the perioperative period of patients undergoing knee arthroplasty - a Nordic perspective. J Clin Nurs. 2014;23(19-20): 2896-2908.

28. Klemetti S, Leino-Kilpi H, Charalambous A, et al. Information and control preferences and their relationship with the knowledge received among European joint arthroplasty patients. Orthopaed Nurs. 2016; 35(3):174-182.

29. Leino-Kilpi H, Heikkinen K, Hiltunen A, et al. Preference for information and behavioral control among adult ambulatory surgical patients. Appl Nurs Res. 2009;22(2):101-106.

30. Bursac Z, Gauss CH, Williams DK, Hosmer DW. Purposeful selection of variables in logistic regression. Source Code Biol Med. 2008;3(1):17.

31. McHugh ML. Interrater reliability: the kappa statistic. Biochem Med. 2012;22(3):276-282. 
32. Bruera E, Sweeney C, Calder K, Palmer L, Benisch-Tolley S. Patient preferences versus physician perceptions of treatment decisions in cancer care. J Clin Oncol. 2001;19(11):2883-2885.

33. Bruera E, Willey JS, Lynn Palmer J, Rosales M. Treatment decisions for breast carcinoma. Cancer. 2002;94(7):2076-2080.

34. Tattersall MH, Kissane DW. Achieving shared treatment decisions. Oxford Textbook Commun Oncol Palliat Care. Oxford University Press: UK. 2017;83.

35. Benbassat J, Pilpel D, Tidhar M. Patients' preferences for participation in clinical decision making: a review of published surveys. Behav Med. 1998;24(2):81-88.

36. Arora NK, McHorney CA. Patient preferences for medical decision making: who really wants to participate? Med Care. 2000;38(3): $335-341$.
37. Giordano A, Mattarozzi K, Pucci E, et al. Participation in medical decision-making: attitudes of Italians with multiple sclerosis. J Neurol Sci. 2008;275(1):86-91.

38. Tariman JD, Berry DL, Cochrane B, Doorenbos A, Schepp K. Preferred and actual participation roles during health care decision making in persons with cancer: a systematic review. Ann Oncol. 2010;21(6): 1145-1151.

39. Florin J, Ehrenberg A, Ehnfors M. Clinical decision-making: predictors of patient participation in nursing care. J Clin Nurs. 2008;17(21): 2935-2944.

\section{Publish your work in this journal}

Patient Preference and Adherence is an international, peer-reviewed, open access journal that focuses on the growing importance of patient preference and adherence throughout the therapeutic continuum. Patient satisfaction, acceptability, quality of life, compliance, persistence and their role in developing new therapeutic modalities and compounds to optimize clinical outcomes for existing disease states are major areas of interest for the journal. This journal has been accepted for indexing on PubMed Central. The manuscript management system is completely online and includes a very quick and fair peer-review system, which is all easy to use. Visit http://www. dovepress.com/testimonials.php to read real quotes from published authors.

Submit your manuscript here: http://www.dovepress.com/patient-preference-and-adherence-journal 